\title{
Identification of transmission chains and clusters associated with COVID-19 in Tunisia
}

Mouna Safer ${ }^{1,2^{*}}$ D, Hejer Letaief ${ }^{1,2}$, Aicha Hechaichi ${ }^{1,2}$, Chahida Harizi ${ }^{3}$, Sonia Dhaouadi ${ }^{1}$, Leila Bouabid ${ }^{1}$, Sondes Darouiche ${ }^{1}$, Donia Gharbi ${ }^{1}$, Nawel Elmili', Hamida Ben Salah ${ }^{1}$, Mongi Hammami ${ }^{1}$, Khouloud Talmoudi $^{1}$, Rim Moussa ${ }^{4}$, Nejib Charaa ${ }^{4}$, Hasna Termiz ${ }^{4}$, Fethi Ltaief ${ }^{4}$, Habib Tounekti ${ }^{4}$, Mohamed Makhlouf ${ }^{4}$, Asma Belguith Sriha ${ }^{5}$, Manel Ben Fredj ${ }^{5}$, Sonia Khalfallahn ${ }^{4}$, Houcine Jabrane ${ }^{4}$, Selma Mchirgui ${ }^{4}$, Chedli Amich ${ }^{4}$, Radhia Dabghi ${ }^{4}$, Zid Anez ${ }^{4}$, Latifa Abdelkader ${ }^{4}$, Moncef Mhamdi ${ }^{4}$, Nabil Ouerfeli ${ }^{4}$, Salah Zoghlami ${ }^{4}$, Souha Bougatef ${ }^{1,2}$, Mohamed Kouni Chahed ${ }^{6}$ and Nissaf Bouafif Ben Alaya ${ }^{1,2}$

\begin{abstract}
Background: The aim of this study was to characterize the transmission chains and clusters of COVID-19 infection in Tunisia.

Methods: All cases were confirmed by Reverse Transcriptase Polymerase Chain Reaction of a nasopharyngeal specimen. Contact tracing is undertaken for all confirmed cases in order to identify close contacts that will be systematically screened and quarantined. Transmission chains were identified based on field investigation, contact tracing, results of screening tests and by assessing all probable mode of transmission and interactions.

Results: As of May 18, 2020, 656 cases out of a total of 1043 confirmed cases of Coronavirus disease 2019 belong to 127 transmission chains identified during the epidemic (mean age 42.36 years, Standard deviation 19.56 and sex ratio 0.86). The virus transmission is the most concentrated in the governorate of Tunis (31.5\%), Ariana (10.2\%) and Ben Arous (10.2\%). Virus transmission occurred 50 times (9.72\% of secondary transmission events) between two different governorates. A maximum of seven generations of secondary infection was identified, whereas $62 \%$ of these secondary infections belong the first generation. A total of 11 "super spreader" cases were identified in this investigation. Four large clusters have been identified. The evolution of secondary cases highlighted two peaks: one in 2nd April and a second in $16^{\text {th }}$ April whereas imported cases caused local transmission of virus during the early phase of the epidemic.
\end{abstract}

Conclusion: Correct contact tracing and early active case finding is useful to identify transmission chains and source of infection in order to contain the widespread transmission in the community.

Keywords: COVID-19, Coronavirus infections / transmission, Contact tracing, Cluster analysis, Public health, Tunisia

\footnotetext{
*Correspondence: safermuna@yahoo.fr

${ }^{1}$ National Observatory of New and Emerging Diseases, Ministry Of Health, Tunis, Tunisia

${ }^{2}$ Cardio Vascular Disease Epidemiology and Prevention Research Laboratory, Faculty of Medicine, University of Tunis El Manar, Tunis, Tunisia

Full list of author information is available at the end of the article
}

(c) The Author(s). 2021 Open Access This article is licensed under a Creative Commons Attribution 4.0 International License, which permits use, sharing, adaptation, distribution and reproduction in any medium or format, as long as you give appropriate credit to the original author(s) and the source, provide a link to the Creative Commons licence, and indicate if changes were made. The images or other third party material in this article are included in the article's Creative Commons. licence, unless indicated otherwise in a credit line to the material. If material is not included in the article's Creative Commons licence and your intended use is not permitted by statutory regulation or exceeds the permitted use, you will need to obtain permission directly from the copyright holder. To view a copy of this licence, visit http://creativecommons.org/licenses/by/4.0/. The Creative Commons Public Domain Dedication waiver (http://creativecommons.org/publicdomain/zero/1.0/) applies to the data made available in this article, unless otherwise stated in a credit line to the data. 


\section{Background}

Since December 2019, the world is experiencing a serious health crisis caused by the emergence of a new coronavirus, known SARS-CoV-2 as "Severe Acute Respiratory Syndrome 2" causing a respiratory distress syndrome, called COVID-19 as "Coronavirus disease 2019" [1]. Isolated for the first time in the city of Wuhan in the province of Hubei in China, this virus has already demonstrated its high infectivity even during the asymptomatic phase and its potential to generate explosive outbreaks [2, 3]. As of May 20, more than 300 countries and territories have reported cases of COVID-19, including more than 4 million confirmed cases and over 300,000 attributable deaths worldwide [4]. In response to this "alarming levels of spread and severity", the World Health Organization (WHO) declared COVID-19 a public health emergency of international concern on 30 January 2020 [5] and then a pandemic on 11 March 2020 [6].

One of strategic objectives adopted by WHO in the response to COVID-19 rapid global spread was to "Interrupt human-to-human transmission including reducing secondary infections among close contacts and health care workers, preventing transmission amplification events, and preventing further international spread" [7] . The International Health Regulations (IHR) Emergency Committee stated in its second meeting that it "believes that it is still possible to interrupt virus spread, provided that countries put in place strong measures to detect disease early, isolate and treat cases, trace contacts" [8].

On March 2, 2020, Tunisia reported its first confirmed case of COVID-19 infection. in a 40-year-old man who had a history of travel in Italy [9]. Since this date, other imported cases were identified, followed by chains of secondary infection. As of May 18, 2020, the cumulative number of confirmed COVID-19 cases was 1043(252 imported and 791 local) corresponding to a cumulative incidence of 8.80/100000. Among COVID-19 confirmed cases $17.1 \%$ were still active. Fatality rate was $4.4 \%$ and the proportion of health care professionals infected was $13.6 \%$.

Early preventive measures were put in place by the Tunisian government since 22 January 2020 (screening in points of entry and systematic 14 days isolation of travelers returning from risk areas). First preventive measures after the confirmation of the first case have been implemented (9-20 March 2020) including partial border closure, closure of schools and universities and curfew from $6 \mathrm{pm}$ to $6 \mathrm{am}$ (since 18 th March). On March 20, a national lockdown, was applied until 4 May the date of implementation of a targeted and progressive containment (return of commercial activities: $50 \%$ for large companies and $100 \%$ for small ones).
As it's well documented that identification of the chain of disease transmission and the source of infection are crucial for guiding effectively containment measures [10], investigation was immediately activated to identify cases and contacts and to analyze transmission and super spreading events.

The aim of this study was to characterize the transmission chains and clusters of COVID-19 infection in the current Tunisian outbreak until May 2020.

\section{Methods}

\section{Study design and population}

This outbreak investigation was carried out as collaboration between the national level (Observatory of New and Emerging Diseases) and the regional level (Public Health Surveillance Departments). It concerned all patients with confirmed SARS-CoV-2 infection and close contacts of these patients.

\section{Definitions}

MERS-CoV-2 infection was confirmed by positive realtime Reverse Transcriptase Polymerase Chain Reaction (RT-PCR) assays in one nasopharyngeal sample. Close contacts were defined as person having any contact within $1 \mathrm{~m}$ and cumulative face-to-face contact exceeding $15 \mathrm{~min}$ with a COVID-19 confirmed case. The day of symptom onset was defined as the day when any symptom (specific or nonspecific) occurred. A transmission pair was defined when two confirmed COVID-19 cases meet the following criteria:1/A clear epidemiologic link was established; $2 /$ the infectee patient don't have a history of travel to an area affected by COVID-19; 3/all other confirmed cases with an exposure history that didn't allow to precise the source of the infection were excluded. So the transmission of an infectee patient can be only attributed to one infector whereas a patient could be infectee and infector in the same time.

Tracing and screening strategy: The contact tracing strategy was based on the rapid identification of all symptomatic and asymptomatic close contacts, application of self-isolation for 14 days and systematic screening of COVID-19 based on RT-PCR test. All close contacts in self-isolation were surveilled in order to detect symptoms indicating a second test. Quarantine was undertaken in home for close contacts and in specific structures for confirmed cases.

\section{Data sources and identification of transmission chains and infector/infectee pairs}

Data allowing the analysis of transmission chains were the following:

1/ Individual-level data on infected patients was extracted from the "Tunisian daily COVID- 19 confirmed cases database": the main following variables 
were extracted: age, sex, date of reporting case, date of symptom onset and the type of transmission of index cases (local or imported); 2/In Tunisia, as soon as a COVID-19 case was confirmed contact tracing was immediately undertaken by assessing activity patterns, from 14 days preceding symptom(s) onset until isolation and active case-finding among close contact was performed. All contacts were placed under quarantine for 14 days from last exposure to the individual with confirmed COVID-19 at home.

In a first stage the contact and exposure history was based on case interviews made by the regional investigator with the patients and/or their family members. As a second stage, in order to identify the final transmission chains and clusters and to precise different generations of secondary transmission, an epidemiologist of national level discussed with the field regional epidemiologist collaborator or directly with patients whose index cases or circumstances of transmission are uncertain.

\section{Identification of transmission chains and infectee / infector pairs}

Activity maps collected in the contact tracing was analyzed and cross checked with data collected during additional investigation concerning circumstances and dates of exposure in order to identify links between cases and clusters.

Generations of secondary infection were defined as following: 1/Secondary cases were classified as firstgeneration infections if there was a history of direct contact with the index patient; 2 / for the generations following the first one, we defined " $n$ " generation infection referring to those with exposure to " $n-1$ " confirmed patients.

The infectee/ infected pairs were directly deduced from the transmission chains specifying all the generations of secondary transmission.

\section{Analysis of transmission dynamic}

The main characteristic of transmission chains was summarized: total of transmission chains, total of secondary infections, generations of secondary infection, imported primary cases, infector/infectee pairs. The four largest clusters were analyzing by specifying the cluster location, the cluster size, the transmission mode of primary case, reporting date of first and last cases and events occurring the transmission in the cluster. We identified "super spreader" case of COVID-19 and we use for this the same definition adopted by the epidemiologists during the SARS outbreak: "super-spreader" is individual with transmission of SARS to at least eight contacts [11]. Drawing of transmission chains was performed using NetDraw 2.158 [12].

\section{Ethics approval}

As conducted in response to a public health emergency, this epidemiological investigation, analysis of data and containment measures implemented in order to control the spread of the outbreak are exempted from ethical approval. Confidentiality of data was performed using key.

\section{Results}

As of May 18, 2020, 656 cases (133 index cases and 523 cases of secondary infection) out of a total of 1043 confirmed cases of COVID-19 belong to 127 transmission chains identified during the epidemic (mean age 42.36 years, Standard deviation 19.56 and sex ratio 0.86). The analysis of transmission mode among primary cases showed a proportion of $44.1 \%$ of imported cases (Table 1 , Fig. 1).

The distribution of these chains by governorate was summarized in Table 1: the virus transmission is the most concentrated in the governorate of Tunis (31.5\%), Ariana (10.2\%) and Ben Arous (10.2\%). Virus transmission occurred 50 times $(9.72 \%$ of secondary transmission events) between two different governorates. The median of secondary cases linked to the index case was 2 (minimum of 1 and maximum of 106). A total of 513 infector-infectee pairs were identified with 66 COVID-19 positive cases at the same time infector and infectee. A maximum of seven generations of secondary infection was identified when establishing the transmission chains that took place in the governorate of Kebili whereas $62 \%$ of these secondary infections belong the first generation (Fig. 2). A total of 11 "super spreader" cases were identified in this investigation occurring 123 secondary transmission events (Table 1). Among these super spreaders ten were symptomatic the range of super spreader's ages was 28-80. Four large clusters with a number of secondary cases exceeding 20 have been identified. The main characteristics, circumstances and dynamics of the transmission occurring in these clusters were shown in Table 2. The evolution of secondary cases during this investigation is represented in Fig. 3. This evolution highlighted two peaks: one in April 2 and a second in April 16. The evolution of index cases and their distribution in local/imported was shown in Fig. 4, imported cases caused local transmission of virus during early phase of the epidemic (until 20 March 2020 there were $67 \%$ of imported cases among the total index cases). A total of 28 deaths were reported among the 656 cases belonging transmission chains (Fig. 1).

A total of ten healthcare associated COVID-19 infections were documented corresponding all to one generation of secondary infection. (Two transmissions from 
Table 1 Characteristic of 127 transmission chains of COVID 19, Tunisia March-May 2020

\begin{tabular}{|c|c|c|c|c|c|c|c|c|c|}
\hline \multirow[t]{2}{*}{ Governorate } & \multicolumn{2}{|c|}{ Transmission chains } & \multicolumn{2}{|c|}{ Imported primary cases } & \multirow{2}{*}{$\begin{array}{l}\text { Secondary } \\
\text { transmission } \\
\text { cases } \\
\text { (Maximum) }\end{array}$} & \multirow{2}{*}{$\begin{array}{l}\text { Generation } \\
\text { of secondary } \\
\text { transmission } \\
\text { (Maximum) }\end{array}$} & \multirow{2}{*}{$\begin{array}{l}\text { Infector- } \\
\text { infectee } \\
\text { pairs }\end{array}$} & \multirow{2}{*}{$\begin{array}{l}\text { Infector } \\
\text { and } \\
\text { infectee COVID } \\
19 \text { case }\end{array}$} & \multirow{2}{*}{$\begin{array}{l}\text { Super } \\
\text { spreader } \\
\text { cases }\end{array}$} \\
\hline & $\mathbf{n}$ & $\%$ & $\mathbf{n}$ & $\%$ & & & & & \\
\hline Tunis & 40 & 31.5 & 15 & 37.5 & 23 & 4 & 121 & 13 & 3 \\
\hline Ariana & 13 & 10.2 & 9 & 69.2 & 6 & 2 & 28 & 2 & - \\
\hline Ben arous & 13 & 10.2 & 4 & 30.8 & 5 & 2 & 33 & 3 & - \\
\hline Medenine & 9 & 7.1 & 7 & 77.8 & 11 & 2 & 33 & 2 & 1 \\
\hline Sfax & 9 & 7.1 & 6 & 66.7 & 9 & 3 & 24 & 3 & - \\
\hline Sousse & 8 & 5.5 & 2 & 28.6 & 12 & 2 & 37 & 3 & - \\
\hline Gafsa & 5 & 4.7 & - & - & 19 & 3 & 34 & 4 & 1 \\
\hline Monastir & 6 & 4.7 & 3 & 50.0 & 4 & 2 & 10 & 1 & - \\
\hline Tataouine & 4 & 3.1 & 1 & 25.0 & 5 & 2 & 19 & 2 & - \\
\hline Bizerte & 3 & 2.4 & 2 & 66.7 & 10 & 2 & 11 & 0 & - \\
\hline Mahdia & 3 & 2.4 & 1 & 33.3 & 8 & 3 & 9 & 1 & - \\
\hline Manouba & 3 & 2.4 & - & - & 32 & 3 & 33 & 0 & 1 \\
\hline Gabes & 2 & 1.6 & 1 & 50.0 & 12 & 3 & 14 & 3 & 1 \\
\hline Kef & 2 & 1.6 & - & - & 3 & 1 & 4 & 0 & - \\
\hline Nabeul & 3 & 1.6 & 1 & 50.0 & 3 & 2 & 4 & 0 & - \\
\hline Zaghouan & 2 & 1.6 & 1 & 50.0 & 1 & 1 & 1 & 0 & - \\
\hline Kairouan & 1 & 0.8 & 1 & 100.0 & 1 & 1 & 3 & 0 & - \\
\hline Kasserine & 1 & 0.8 & - & - & 2 & 1 & 2 & 0 & - \\
\hline Kebili & 1 & 0.8 & 1 & 100.0 & 106 & 7 & 93 & 29 & 4 \\
\hline Total & 127 & 100.0 & 55 & 43.3 & 106 & 7 & 513 & 66 & 11 \\
\hline
\end{tabular}

health professional to patient; 5 transmissions between health professional and 3 transmissions from patient to health professional).

\section{Discussion}

In response to the rapid global spread of COVID-19 and in presence of local secondary infections, the understanding of the transmission dynamics of the virus is crucial to guide effectively containment measures and interrupt the spread of the virus. In this context, this is the first study documenting transmission chains and clusters of SARS-CoV-2 in Tunisia. This investigation showed how contact tracing and early investigation, upon a case of COVID-19 was confirmed, was crucial to document locally transmission and identify transmission chains. Using these methods, most possible sources of exposure could be identified and most clusters could be documented. This surveillance method is indicated to identify cases in the community and this will be missed if we focus only on symptomatic person and it is the most effective way to enable containment measures in order to stop super spreading events and transmission of the virus [10].
Analysis of transmission chains at early stage of the epidemic before implementation of control measures highlighted the sustained transmission of the SARSCoV-2 in Tunisia. In fact, $47 \%$ of secondary cases were detected during the first month of the spread the virus in Tunisia (March). This sustained transmission was demonstrated also in a recent publication [13] which concluded to a temporal reproduction number $\mathrm{R}_{0}$ of $3.18,95 \%$ CI [2.73-3.69].

The evolution of secondary cases showed two peaks: the first one occurring on April 2 was probably related to the lack of compliance to home quarantine among travelers coming from high-risk countries. Whereas the second peak, of April 16 could be the consequence of the delayed effect of non-compliance with general confinement measures related to mass gatherings as weddings, meetings and funerals.

The "Super spreaders" identified in this investigation have significantly participated in the spread of the disease. In fact, these 9 "Super spreaders" had transmitted the infection to a total of 95 close contact people. Similar events were associated with outbreaks of SARS and MERS [11, 14, 15] and reported recently with SARSCoV-2 [16]. 

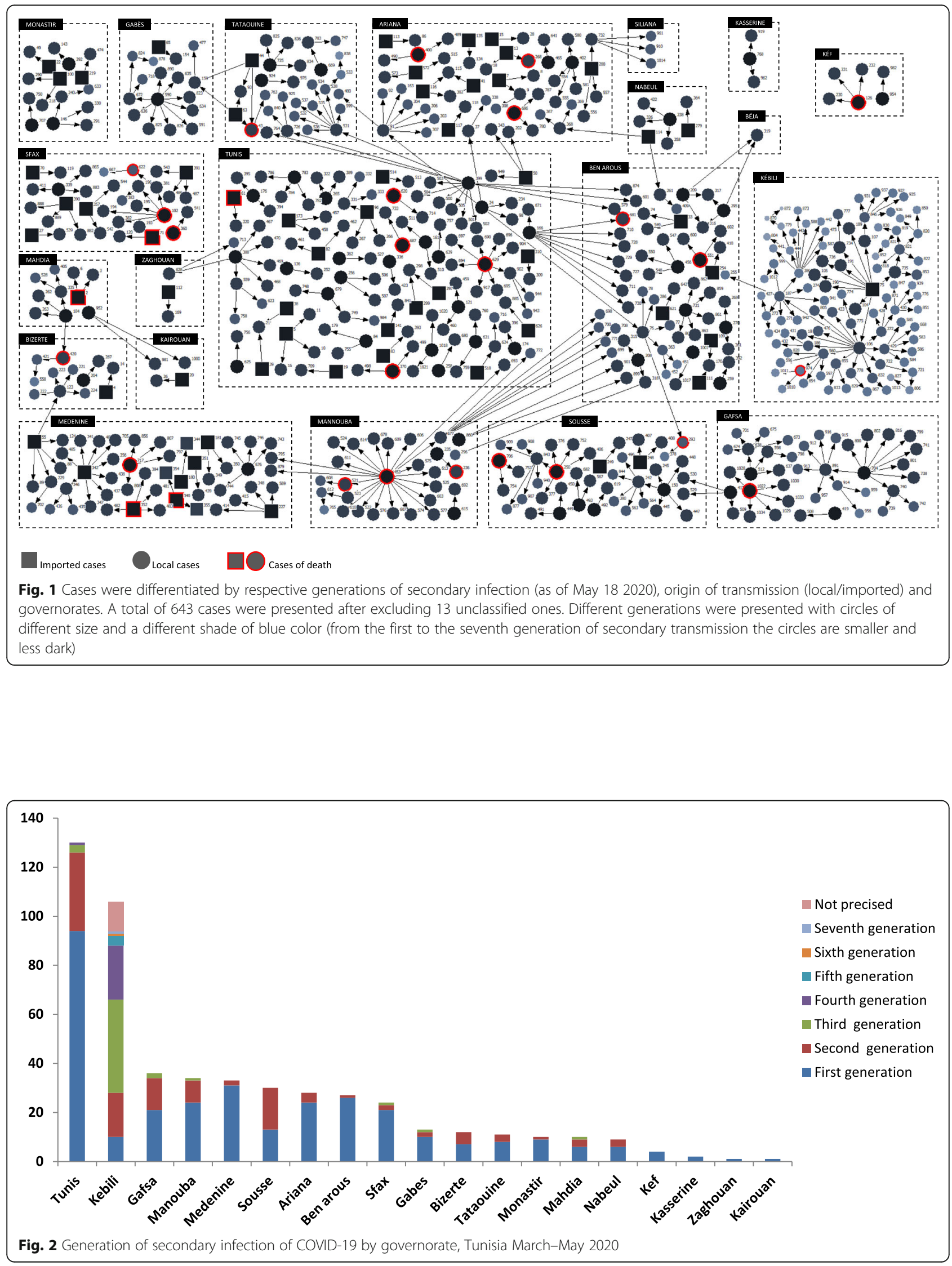
Table 2 Characteristics of the largest COVID-19 clusters in Tunisia March-May 2020

\begin{tabular}{llllllll}
\hline $\begin{array}{l}\text { Cluster } \\
\text { identification }\end{array}$ & $\begin{array}{l}\text { Cluster } \\
\text { location }\end{array}$ & $\begin{array}{l}\text { Cluster } \\
\text { size }\end{array}$ & $\begin{array}{l}\text { Transmission mode } \\
\text { of primary case }\end{array}$ & $\begin{array}{l}\text { Generation of } \\
\text { secondary } \\
\text { transmission }\end{array}$ & $\begin{array}{l}\text { Reporting date } \\
\text { for the first case }\end{array}$ & $\begin{array}{l}\text { Reporting date } \\
\text { for the last case }\end{array}$ & $\begin{array}{l}\text { Transmission } \\
\text { events }\end{array}$ \\
\hline Cluster $\mathbf{1}$ & Kebili & 108 & Imported & 7 & $21 / 03 / 2020$ & $05 / 05 / 2020$ & $\begin{array}{l}\text { Family gathering/wedding } \\
\text { ceremony }\end{array}$ \\
Cluster $\mathbf{2}$ & Manouba & 33 & Local & 3 & $31 / 03 / 2020$ & $03 / 04 / 2020$ & Family gathering \\
Cluster $\mathbf{3}$ & Tunis & 24 & Local & 3 & $31 / 03 / 2020$ & $24 / 04 / 2020$ & Family gathering \\
Cluster $\mathbf{4}$ & Tunis & 22 & Local & 3 & $16 / 03 / 2020$ & $03 / 04 / 2020$ & Conferences/meetings \\
\hline
\end{tabular}

Concerning the evolution of the index cases, we have noted that imported cases contribute to secondary disease transmission in Tunisia at the early phase of the epidemic. This finding support the impact of government measures put in place such as travel restrictions since March 20 and mandatory quarantine of repatriated population since March 22.

As a consequence of the mounting number of COVD19 cases in Tunisia and the sustained transmission, the government implemented many control measures from 18 March: curfew, lockdown, travel restrictions, social distancing measures including restriction of public transportation, cancelling of social and mass gathering events, school and university closure, and some professional activities as well as promotion of preventive measures among general population (barrier measures, physical distance, hand washing) and among health workers (Personal Protective Equipment and care hygiene).

In this study the four largest clusters showing a local transmission were analyzed. Transmission of infection in these clusters was probably attributed to close and prolonged contacts with symptomatic case and was occasioned by family gatherings (clusters 1,2 and 3 ), a wedding ceremony (cluster1), a conference and meetings (cluster 4). Direct physical contact and handshaking was reported in family gatherings and meetings. In the wedding event (cluster 1 ), and one of family gatherings (cluster 1) sharing of meals during a ceremonial dinner was also reported.

These findings are similar to those shown in other published case series analyzing transmission chains. In fact, transmission by close contact is known as the most common transmission mode particularly when contact is prolonged [17]. Whereas the possibility of indirect transmission can't be excluded since surface contamination and indirect transmission (via fomites and shared food) has been documented in some studies and this evidence emphasizes the importance to sensitize community to adopt strict personal and hand hygiene as a key preventive measure [18].

We recognized that this study had some limitations and some results should be interpreted carefully. First, as symptom onset dates and close contacts were selfreported, there could have been reporting information bias.

To mitigate these biases we collected information immediately after case confirmation. However, biases concerning the identification of close contacts could not be completely eliminated since this identification is mainly based on the statements of patients and contacts, nevertheless we explained the exact meaning of a "close

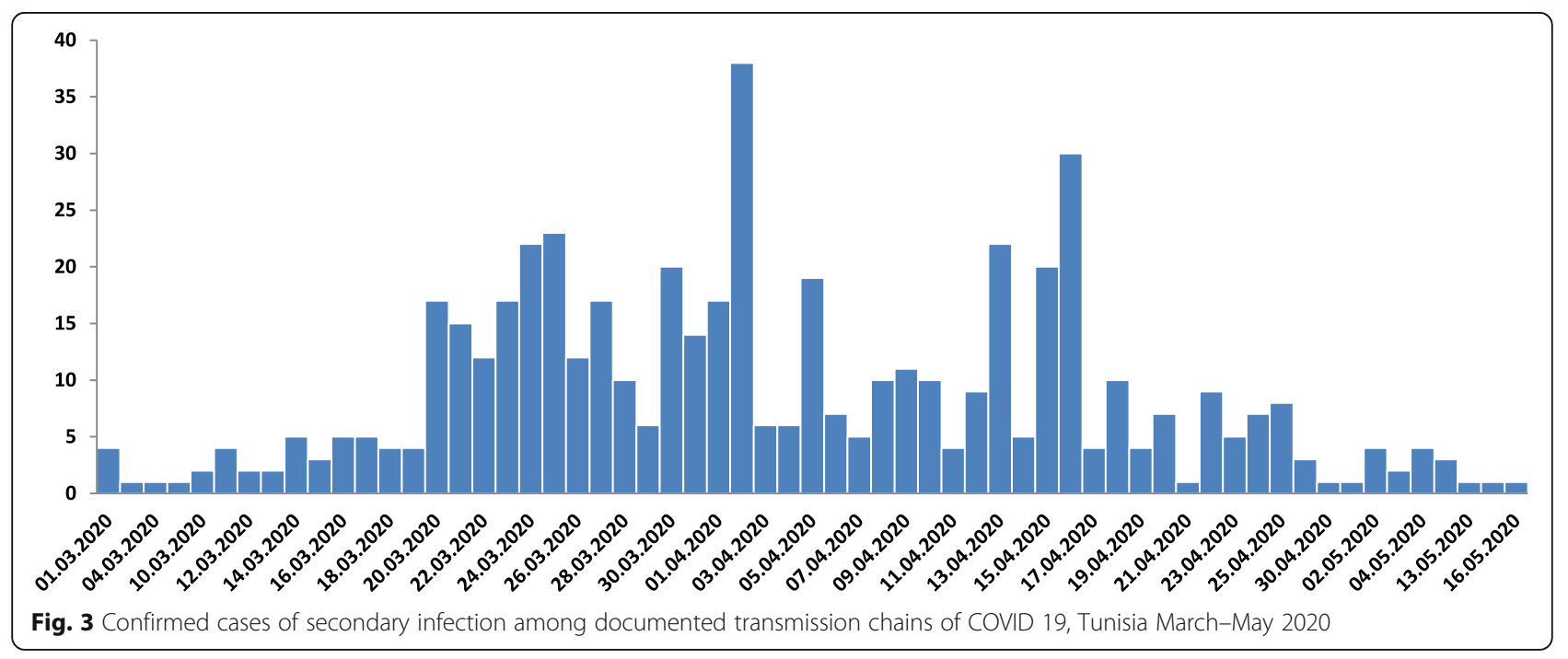




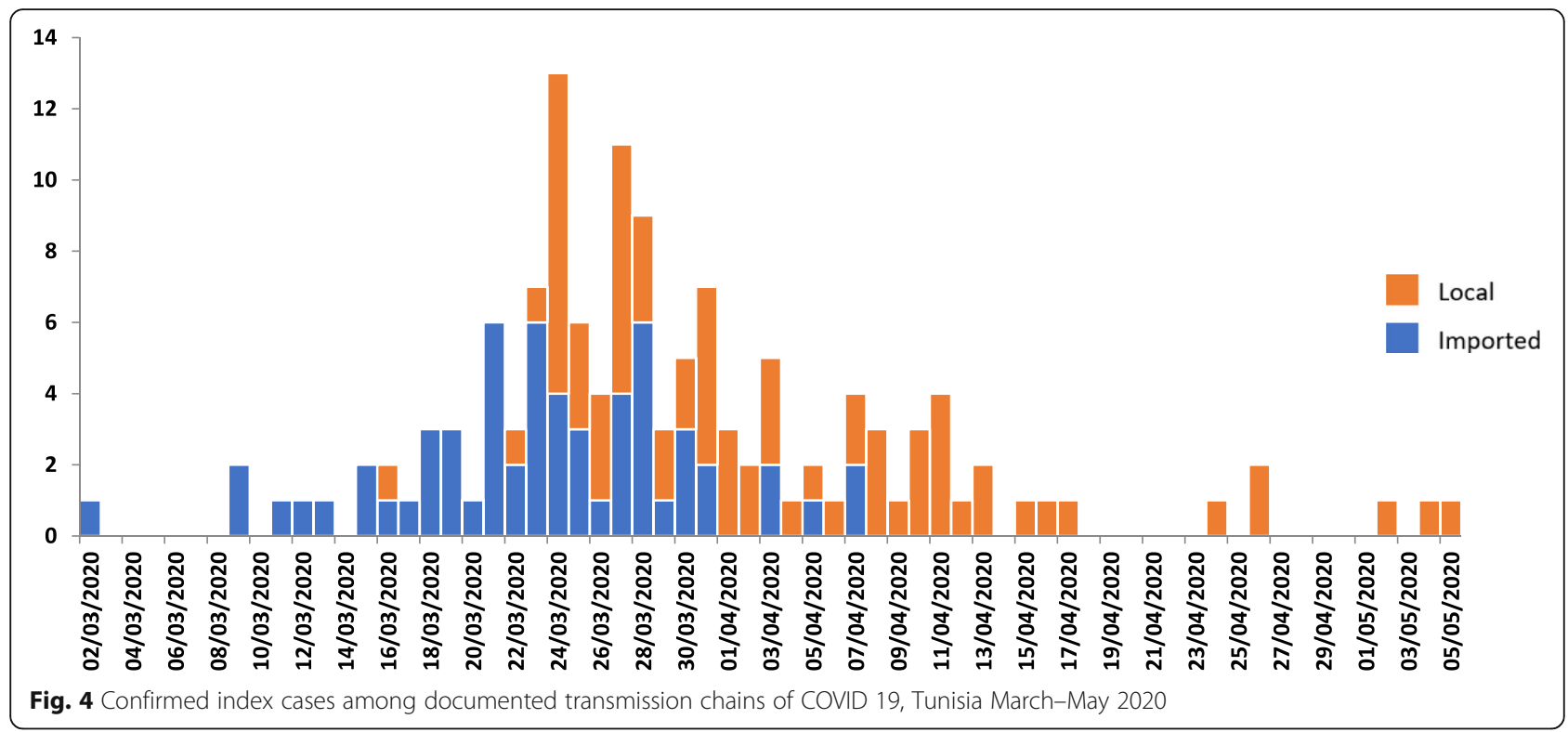

contact" to all interviewees and we collected all the exposure history in order to define accurately all close contacts.

Second limitation concerned the use of only RT-PCR testing in active case-finding among close contacts. This method is known to offer a rapid diagnostic solution, but it can only detect SARS-CoV-2 during the period of viral shedding which still not certain and RT-PCR is so limited by its ability to detect convalescent cases of COVID-19 [19]. The first preliminary analysis [20] of SARS-CoV-2 IgM and IgG indicated that the antibody response in COVID-19 patients is similar to seroconversion kinetics indicated with Middle East respiratory syndrome (3 weeks after symptoms started) [21] and with severe acute respiratory syndrome (93\% of patients seroconverted at an average of 20 days from symptom onset) [22], if not earlier than, these times.

Serological testing were demonstrated in a recent study [17], to have a crucial role in identifying convalescent cases or people with milder disease who might have been missed by RT-PCR and helped so to establish connections between COVID-19 clusters. This will be useful for epidemiological investigation by identifying more accurately infected people in clusters and track transmission dynamics which would better inform disease control policies for more or less containment efforts. It is also crucial to determine more accurately the number of infected patients because this will influence all other epidemiological estimations: such attack rates and case fatality rate.

Some difficulties were noted during this first step of outbreak investigation aimed to identify transmission chains of COVD-19. Difficulties concerned mainly the use of traditional epidemiologic methods to establish links between cases and clusters, which were sources of delays and inaccuracy to obtain information from cases and contacts so that the implementation of tracking device that will help to achieve contact tracing in a precise and valid manner is necessary in the next steps of the management of the epidemic.

The other perspectives in the next phases of epidemic management allowing to improve the identification of links between cases and between clusters concern adoption of additional laboratory techniques, such as serological tests and phylogenetic analysis, as well as the acquisition and activation of applications allowing accurate detection of close contacts and quarantine violators, enabling identification new close contacts in a timely manner.

\section{Conclusion}

All the efforts made during the management of the epidemic of COVID-19 in Tunisia by conducting properly contact tracing and active case-finding facilitated the documentation of transmission chains and the identification of sources of infection. This rigorous approach was of great help to guide the containment measures and stop the spread of the epidemic and supports evidence that these measures were effective.

\section{Abbreviations}

COVID-19: Coronavirus Disease 2019; RT-PCR: Reverse Transcriptase Polymerase Chain Reaction; SARS-CoV-2: Severe Acute Respiratory Syndrome Corona Virus 2; SARS: Severe Acute Respiratory Syndrome; IgM: Immunoglobulin M; IgG: Immunoglobulin G

\section{Acknowledgements}

We acknowledge all field teams of the regional Public Health Surveillance Departments involved in investigation and case tracing, as well as the lab team contributing to the laboratory diagnosis based on the real-time RT-PCR test.

\section{Authors' contributions}

At the national level: Observatory of New and Emerging Diseases: MC and NBA conceived the study. MS, KT and AH performed data analysis. MS,SB, HL, $\mathrm{AH}, \mathrm{CH}, \mathrm{SDA}, \mathrm{HBS}, \mathrm{NE}, \mathrm{SD}, \mathrm{LB}$ and $\mathrm{DG}$ collected and managed outbreak 
investigation and contact tracing data. $\mathrm{MH}$ drew transmission chains using NetDraw 2.158. SM drafted the first manuscript. NBA revised the manuscript. All authors, critically read and revised the manuscript, and give final approval for publication. At the regional level: RM, NC, HT, FL, HTO, MM, SBA, MBF, SK, $H J, S M, C A, R D, Z A, A L, M M H, N O, S Z$ are the investigator at the regional level, they managed outbreak investigation, contact tracing and discussed with the epidemiologist at the national level the final transmission chains and the generations of secondary infections.

\section{Funding}

This research received no specific grant from any funding agency in the public, commercial or not-for-profit sectors'. WHO Tunisia Office supports the open access fees of this article when accepted.

\section{Availability of data and materials}

The National Observatory of New and Emerging Diseases (Tunisia) as well as the corresponding author had full access to all data. This data wasn't publicly accessible but available from the corresponding author upon reasonable request.

\section{Declarations}

\section{Ethics approval and consent to participate}

Data collection and analysis were required by the Tuinisia's National multidisciplinary commission for COVID-19 as a part of public health outbreak investigation and response. As conducted in response to a public health emergency, this epidemiological investigation, analysis of data and containment measures implemented in order to control the spread of the outbreak are exempted from ethical approval (Law No. 2007-12 of 12 February 2007 amending and supplementing Law No. 92-71 of 27 July 1992 on communicable diseases stipulating; Article 11 (bis):. All tracing and other epidemilogical data were collected from National Observatory of New and Emerging Diseases of Tunis, Tunisia (Main National Structure of epidemiologic Surveillance in tunisia: Decree No. 2005-3294 of 19 December 2005, Article 3). Administrative permissions were required to access and use the meta-data described in our study. Permission was granted from the National Observatory of New and Emerging Diseases. Data used in this study was anonymised before its use. Neither ethical approval nor individual consent was not applicable.

\section{Consent for publication}

Not applicable.

\section{Competing interests}

Authors declare no conflict of interest.

\section{Author details}

${ }^{1}$ National Observatory of New and Emerging Diseases, Ministry Of Health, Tunis, Tunisia. ${ }^{2}$ Cardio Vascular Disease Epidemiology and Prevention Research Laboratory, Faculty of Medicine, University of Tunis El Manar, Tunis, Tunisia. ${ }^{3}$ Department of Epidemiology and Statistics, Abderrahman Mami Hospital, Ariana, Tunisia. ${ }^{4}$ Public Health Surveillance Regional Departments, Tunis, Tunisia. ${ }^{5}$ Department of Community and Preventive Medicine Faculty of Medicine, University of Monastir Tunisia, Tunis, Tunisia. ${ }^{6}$ Department of Epidemiology and Public Health, Faculty of Medicine of Tunis, Tunis El-Manar University, Tunis, Tunisia.

\section{Received: 13 October 2020 Accepted: 22 April 2021}

Published online: 19 May 2021

\section{References}

1. (WHO) WHO. Naming the coronavirus disease (COVID-19) and the virus that causes it 2020 [cited 20201 june ]. Available from: https://www.who.int/ emergencies/diseases/novel-coronavirus-2019/technical-guidance/namingthe-coronavirus-disease-(covid-2019)-and-the-virus-that-causes-it.

2. Mizumoto K, Kagaya K, Chowell G. Early epidemiological assessment of the transmission potential and virulence of 2019 Novel Coronavirus in Wuhan City: China, 2019-2020. medRxiv. 2020. https://doi.org/10.1101/2020.02.12.20022434.

3. Mizumoto K, Chowell G. Transmission potential of the novel coronavirus (COVID-19) onboard the diamond princess cruises ship, 2020. Infect Dis Model. 2020;5:264-70.
4. $(\mathrm{WHO}) \mathrm{WHO}$. Coronavirus disease (COVID-19) Situation Report- 1212020 [cited 202020 May ]. Available from: https:/www.who.int/docs/default-source/corona viruse/situation-reports/20200520-covid-19-sitrep-121.pdf?sfvrsn=c4be2ec6_4.

5. (WHO) WHO. Statement on the meeting of the international health regulations (2005) emergency committee regarding the outbreak of novel coronavirus (2019-nCoV). [cited 202019 May ]. Available from: https://www. who.int/news/item/23-01-2020-statement-on-the-meeting-of-the-interna tional-health-regulations-(2005)-emergency-committee-regarding-theoutbreak-of-novel-coronavirus-(2019-ncov).

6. (WHO) WHO. WHO Director-General's opening remarks at the media briefing on COVID-19 - 11 March 2020. [cited 202020 March ]. Available from: https://www.who.int/director-general/speeches/who-director-generals-opening-remarks-at-the-media-briefing-on-covid-19---11-march-2020.

7. Bal EYÇS. Strategies of the world health organization in the Covid 19 outbreak. J Infect Dis Epidemiol. 2020;6:118.

8. (WHO) WHO. Statement on the second meeting of the International Health Regulations (2005) Emergency Committee regarding the outbreak of novel coronavirus (2019-nCoV). [cited 202020 March ]. Available from: https:// www.who.int/director-general/speeches/who-director-general-s-openingremarks-at-the-media-briefing-on-covid-19---11-march-2020.

9. Chakroun H, Ben LN, Fall S, Maha A, El Moussi A, Abid S, et al. First case of imported and confirmed COVID-19 in Tunisia. Tun Med. 2020;98(4):258-60.

10. Hellewell J, Abbott S, Gimma A, Bosse NI, Jarvis Cl, Russell TW, et al. Feasibility of controlling COVID-19 outbreaks by isolation of cases and contacts. Lancet Glob Health. 2020;8(4):e488-96. https:/doi.org/10.1016/S2214-109X(20)30074-7.

11. Tsang KW, Ho PL, Ooi GC, Yee WK, Wang T, Chan-Yeung M, et al. A cluster of cases of severe acute respiratory syndrome in Hong Kong. N Engl J Med. 2003;348(20):1977-85. https://doi.org/10.1056/NEJMoa030666.

12. Borgatti SP, Everett MG, Freeman LC. Ucinet for windows: software for social network analysis, vol. 6. Harvard: Analytic technologies; 2002.

13. Talmoudi K, Safer M, Letaief H, Hchaichi A, Harizi C, Dhaouadi S, et al. Estimating transmission dynamics and serial interval of the first wave of COVID-19 infections under different control measures: a statistical analysis in Tunisia from February 29 to may 5, 2020. 2020.

14. Cho SY, Kang J-M, Ha YE, Park GE, Lee JY, Ko J-H, et al. MERS-CoV outbreak following a single patient exposure in an emergency room in South Korea: an epidemiological outbreak study. Lancet. 2016;388(10048):994-1001. https://doi.org/10.1016/S0140-6736(16)30623-7.

15. Kang CK, Song K-H, Choe PG, Park WB, Bang JH, Kim ES, et al. Clinical and epidemiologic characteristics of spreaders of Middle East respiratory syndrome coronavirus during the 2015 outbreak in Korea. J Korean Med Sci. 2017;32(5):744-9. https://doi.org/10.3346/jkms.2017.32.5.744.

16. Hu K, Zhao $Y$, Wang $M$, Zeng $Q$, Wang $X$, Wang $M$, et al. Identification of a super-spreading chain of transmission associated with COVID-19. medRxiv. 2020. https://doi.org/10.1101/2020.03.19.20026245.

17. Yong SEF, Anderson DE, Wei WE, Pang J, Chia WN, Tan CW, et al. Connecting clusters of COVID-19: an epidemiological and serological investigation. Lancet Infect Dis. 2020;20(7):809-15. https://doi.org/10.1016/S1473-3099(20)30273-5.

18. Ong SWX, Tan YK, Chia PY, Lee TH, Ng OT, Wong MSY, et al. Air, surface environmental, and personal protective equipment contamination by severe acute respiratory syndrome coronavirus 2 (SARS-CoV-2) from a symptomatic patient. Jama. 2020;323(16):1610-2. https://doi.org/10.1001/jama.2020.3227.

19. Vetter P, Eckerle I, Kaiser L. Covid-19: a puzzle with many missing pieces. Bri Med J. 2020;368:m627.

20. Zhang W, Du R-H, Li B, Zheng X-S, Yang X-L, Hu B, et al. Molecular and serological investigation of 2019-nCoV infected patients: implication of multiple shedding routes. Emerg Microb Infect. 2020;9(1):386-9. https://doi. org/10.1080/22221751.2020.1729071.

21. Corman VM, Albarrak AM, Omrani AS, Albarrak MM, Farah ME, Almasri M, et al. Viral shedding and antibody response in 37 patients with Middle East respiratory syndrome coronavirus infection. Clin Infect Dis. 2016;62(4):47783. https://doi.org/10.1093/cid/civ951.

22. Peiris JSM, Chu C-M, Cheng VC-C, Chan K, Hung I, Poon LL, et al. Clinical progression and viral load in a community outbreak of coronavirusassociated SARS pneumonia: a prospective study. Lancet. 2003;361(9371): 1767-72. https://doi.org/10.1016/S0140-6736(03)13412-5.

\section{Publisher's Note}

Springer Nature remains neutral with regard to jurisdictional claims in published maps and institutional affiliations. 